\title{
Interactions between Atorvastatin and the Farnesoid X Receptor Impair Insulinotropic Effects of Bile Acids and Modulate Diabetogenic Risk
}

\author{
Theresa Hoffmeister, Julia Kaiser, Simon Lüdtke, Gisela Drews, and Martina Düfer \\ Institute of Pharmaceutical and Medicinal Chemistry, Department of Pharmacology, Münster, Germany (T.H., S.L., M.D.) and \\ Institute of Pharmacy, Department of Pharmacology and Clinical Pharmacy, Tübingen, Germany (J.K., G.D.) \\ Received August 8, 2019; accepted December 18, 2019
}

\begin{abstract}
Bile acids such as chenodeoxycholic acid (CDC) acutely enhance insulin secretion via the farnesoid $X$ receptor (FXR). Statins, which are frequently prescribed for patients with type 2 diabetes who suffer from dyslipidemia, are known for their diabetogenic risk and are reported to interact with the FXR. Our study investigates whether this interaction is relevant for beta cell signaling and plays a role for negative effects of statins on glycemic control. Experiments were performed with islets and islet cells from C57BL/6N wild-type and FXR-knockout (KO) mice. Culturing islets with atorvastatin $(15 \mu \mathrm{M})$ for 24 hours decreased glucose-stimulated insulin secretion by approximately $30 \%$ without affecting ATP synthesis. Prolonged exposure for 7 days lowered the concentration necessary for impairment of insulin release to $150 \mathrm{nM}$. After 24-hour culture with atorvastatin, the ability of CDC $(500 \mathrm{nM})$ to elevate $\left[\mathrm{Ca}^{2+}\right]_{c}$ was diminished and the potentiating effect on insulin secretion was completely lost. Mevalonate largely reduced the negative effect of atorvastatin. Nuclear activity of FXR was reduced by atorvastatin in a mouse FXR reporter assay. The atorvastatin-induced decrease in insulin release was also present in FXR-KO mice. Although not
\end{abstract}

\section{Introduction}

Statins prescribed to lower low-density lipoprotein (LDL) cholesterol are in broad clinical use. Their beneficial effects concerning prevention of cardiovascular risk are undisputed (Scandinavian Simvastatin Survival Study study group, 1994; Sever et al., 2003); nevertheless, certain side effects have to be considered (Thompson et al., 2016). A meta-analysis of 13 statin trials with 91,140 participants provides clear evidence that the risk to develop type 2 diabetes mellitus increases in patients during long-term statin therapy (Sattar et al., 2010).

Particularly, lipophilic statins such as atorvastatin are assumed to influence islet function in a detrimental way (Yada et al., 1999; Yaluri et al., 2015; Urbano et al., 2017). Whether this is associated with the hydroxy-methyl-glutaryl coenzyme A (HMG-CoA) reductase inhibition or results from off-target effects, remains controversial. Partly the effects are

This work was financially supported. Parts of this work were supported by a project grant of the Deutsche Diabetes Gesellschaft to M.D

https://doi.org/10.1124/mol.119.118083. a prerequisite, FXR seems to influence the degree of damage caused by atorvastatin depending on its interaction with CDC: Preparations responding to CDC with an increase in insulin secretion under control conditions were less impaired by atorvastatin than preparations that were nonresponsive to CDC. Extended stimulation of FXR by the synthetic agonist GW4064, which is suggested to induce translocation of FXR from the cytosol into the nucleus, increased the inhibitory effect of atorvastatin. In conclusion, atorvastatin inhibits insulin release and prevents positive effects of bile acids on beta cell function. Both interactions may contribute to progression of type 2 diabetes mellitus.

\section{SIGNIFICANCE STATEMENT}

This study shows that the diabetogenic risk of statins is coupled to the activity of farnesoid X receptor (FXR)-dependent signaling pathways in beta cells. On the one hand, statins abolish the insulinotropic effects of bile acids and on the other hand, FXR determines the level of impairment of islet function by the statin.

ABBREVIATIONS: AUC, area under the curve; CDC, chenodeoxycholic acid; FXR, farnesoid X receptor; HMG-CoA, hydroxy-methyl-glutaryl coenzyme $A$; KO, knockout; PXR, pregnane $X$ receptor.

closely linked to the mode of action of statins (Urbano et al., 2017), partly the observed effects are not reversible by a coculture with mevalonate (Yaluri et al., 2015). Interestingly, it was shown that statins interact with pathways regulated by the farnesoid X receptor (FXR). Fu et al. (2014) reported effects of atorvastatin on FXR-induced target genes in mice, whereas Habeos et al. (2005) observed changes in the expression and DNA-binding activity of the receptor in the liver after treatment of Syrian hamsters with simvastatin as well as in simvastatin-treated HepG2 cells.

The FXR is a nuclear receptor targeted by bile acids like chenodeoxycholic acid (CDC), which is the most effective one (Makishima et al., 1999; Parks et al., 1999). It plays a role for regulation of lipid and bile acid metabolism and also for glucose homeostasis (Fiorucci et al., 2009; Düfer et al., 2012a). FXR expression is high in liver, adrenal glands, and intestine (Huber et al., 2002); however, mRNA can also be found in other organs like the endocrine pancreas (Popescu et al., 2010). In our previous work, we investigated the impact of an acute stimulation of the FXR by the bile acid taurochenodeoxycholic 
acid on insulin secretion. We detected an FXR-dependent insulinotropic effect of the bile acid, which includes inhibition of $\mathrm{K}_{\mathrm{ATP}}$ channels, membrane depolarization and increased $\mathrm{Ca}^{2+}$ influx (Düfer et al., 2012b). For this acute stimulatory effect on insulin secretion, cytosolic localization of FXR, and bile acid-induced interaction with $\mathrm{K}_{\mathrm{ATP}}$ channels are essential.

The reported impact of statins on FXR in liver and intestine, respectively (Habeos et al., 2005; Fu et al., 2014), raises the question of a comparable situation in the pancreas. The aim of our study was to gain insight into possible interactions between FXR and statins in pancreatic islets. Therefore, the influence of atorvastatin and its interaction with bile acid signaling was investigated in islets of wild-type and FXRknockout (KO) mice by monitoring membrane potential, cytosolic $\mathrm{Ca}^{2+}$ concentration $\left(\left[\mathrm{Ca}^{2+}\right]_{\mathrm{c}}\right)$, ATP, apoptosis, and insulin release and content. In addition, a reporter assay was used to test for interactions of statins with transcriptional activity of FXR.

\section{Materials and Methods}

Cell and Islet Preparation. Experiments were performed with islets of Langerhans from adult male and female C57BL/6N mice (Charles River, Sulzfeld, Germany) or adult male and female FXRdeficient mice (age of $9 \pm 3$ months) from a C57BL/6N background described earlier (Sinal et al., 2000). The principles of laboratory animal care were followed according to German laws (Az. 53.5.32.7.1/ MS-12668, health and veterinary office Münster, Germany). Mice were euthanized by $\mathrm{CO}_{2}$. Islets were isolated by collagenase digestion. Dispersed cells or smaller cell clusters were obtained by trypsinization and used for membrane potential and $\left[\mathrm{Ca}^{2+}\right]_{\mathrm{c}}$ measurements and for determination of apoptosis. Islets and cells were cultured in RPMI 1640 medium (11.1 mM glucose) supplemented with $10 \%$ fetal calf serum, $100 \mathrm{U} / \mathrm{ml}$ penicillin, and $100 \mu \mathrm{g} / \mathrm{ml}$ streptomycin at $37^{\circ} \mathrm{C}$ in $5 \% \mathrm{CO}_{2}$ humidified atmosphere. After preparation, islets or dispersed islet cells were kept overnight in standard culture medium. The next day, incubation started in the presence of atorvastatin or pravastatin for 24 hours or 7 days. In case of preincubations with GW4064 atorvastatin was added 1 day later. Medium was changed every 2nd or 3rd day during the long-term incubation of 7 days.

Solution and Chemicals. Insulin secretion was performed in bath solution containing [millimolars]: $122 \mathrm{NaCl}, 4.7 \mathrm{KCl}, 1.1 \mathrm{MgCl}_{2}$, $2.5 \mathrm{CaCl}_{2}, 10$ HEPES (pH 7.4) and $0.5 \%$ bovine serum albumin. $\left[\mathrm{Ca}^{2+}\right]_{\mathrm{c}}$, membrane potential and ATP were measured in a solution that contained [millimolars]: $140 \mathrm{NaCl}, 5 \mathrm{KCl}, 1.2 \mathrm{MgCl}_{2}, 2.5 \mathrm{CaCl}_{2}, 10$ HEPES ( $\mathrm{pH}$ 7.4). Pipette solution for electrophysiology contained [millimolars]: $10 \mathrm{KCl}, 10 \mathrm{NaCl}, 70 \mathrm{~K}_{2} \mathrm{SO}_{4}, 4 \mathrm{MgCl}_{2}, 2 \mathrm{CaCl}_{2}, 10 \mathrm{EGTA}$, $20 \mathrm{HEPES}, 250 \mu \mathrm{g} / \mathrm{ml}$ amphotericin B, pH 7.15. Glucose was added as indicated.

Collagenase $\mathrm{P}$ was from Roche Diagnostics (Mannheim, Germany); annexin V reagent was from Essen BioScience (Michigan); RPMI 1640, fetal calf serum, and penicillin/streptomycin were obtained from Life Technologies (Darmstadt, Germany). The statins used were: atorvastatin [IUPAC name: (3R,5R)-7-[2-(4-fluorophenyl)-3-phenyl-4(phenylcarbamoyl)-5-propan-2-ylpyrrol-1-yl]-3,5-dihydroxyheptanoic acid, calcium trihydrate, purity: $\geq 98 \%$ ] and pravastatin [IUPAC name: (3R,5R)-7-[(1S,2S,6S,8S,8aR)-6-hydroxy-2-methyl-8-[(2S)-2-methylbutanoyl] oxy-1,2,6,7,8,8a-hexahydronaphthalen-1-yl]-3,5-dihydroxyheptanoic acid, sodium hydrate, purity: $\geq 98 \%$ ]. Both statins, as well as GW4064 [IUPAC name: 3-[(E)-2-[2-chloro-4-[[3-(2,6-dichlorophenyl)-5-propan-2-yl-1,2-oxazol-4-yl]methoxy]phenyl]ethenyl]benzoic acid] and pregnenolone 16alpha-carbonitrile [IUPAC name: (3S,8S,9S,10R,13S,14S,16R,17S)-17-acetyl-3-hydroxy-10,13-dimethyl$2,3,4,7,8,9,11,12,14,15,16,17$-dodecahydro- $1 H$-cyclopenta[a]phenanthrene-16-carbonitrile], were from Sigma-Aldrich (Taufkirchen,
Germany). Fura-2 AM was ordered from Biotrend (Köln, Germany). Labeled ${ }^{125}$ I-insulin was kindly provided by Sanofi (Frankfurt, Germany), primary and secondary antibodies were from Merck Millipore (Rat Insulin RIA, RI-13K) provided by Biotrend. All other chemicals were from Sigma-Aldrich or Diagonal (Münster, Germany).

Insulin Secretion and Content. Islets were moved to bath solution containing $5.6 \mathrm{mM}$ glucose for 2 hours after a culture period of 22 hours or 7 days in the presence or absence of atorvastatin or pravastatin. During these 2 hours, the statin was still present. Following this, glucose was lowered to $3 \mathrm{mM}$ for 1 hour and bath solution did not contain atorvastatin or pravastatin anymore. Batches of five islets were incubated for 1 hour at $37^{\circ} \mathrm{C}$ with glucose concentrations and substances as described in the respective experiment. Thereafter, supernatant was removed for quantitative analysis and islets were lysed with acid ethanol to determine insulin content. Insulin was quantified by radioimmunoassay using rat insulin as standard.

Annexin V Assay. The live-cell analysis system IncuCyte (Essen BioScience) was used for measurement of apoptosis. By means of this method, cell viability could be monitored over a longer time period, whereas cells were in stable conditions in an incubator.

After preparation, dispersed islet cells were cultured in a 96-well plate overnight. The following day, cells were incubated in the presence or absence of $15 \mu \mathrm{M}$ atorvastatin. $50 \mu \mathrm{M} \mathrm{H}_{2} \mathrm{O}_{2}$ was used as a positive control. After adding annexin $\mathrm{V}$ green reagent to each well as instructed by the manufacturer, the measurement started for a time period of 44 hours $\left(37^{\circ} \mathrm{C}, 5 \% \mathrm{CO}_{2}\right.$ humidified atmosphere). Changes in fluorescence of annexin $\mathrm{V}$ green reagent were monitored by excitation at $480 \mathrm{~nm}$ every 2 hours.

Determination of $\left[\mathbf{C a}^{2+}\right]_{\mathbf{c}}$. Cells and cell clusters were loaded with the fluorescent dye fura-2-acetoxymethylester (fura-2 AM, $5 \mu \mathrm{M}$, $37^{\circ} \mathrm{C}, 30$ minutes). $\left[\mathrm{Ca}^{2+}\right]_{\mathrm{c}}$ was determined by measuring fluorescence at $515 \mathrm{~nm}$ after alternate excitation with 340 and $380 \mathrm{~nm}$, respectively. Cells were perifused with bath solution containing glucose and substances as indicated.

Electrophysiology. Changes in membrane potential of single islet cells were determined by the perforated-patch configuration of the patch-clamp technique in the current clamp mode (EPC-10 amplifier, HEKA). Giga-seals were obtained at $\sim 24-26^{\circ} \mathrm{C}$ by patch pipettes pulled from borosilicate glass. Cells were perifused with bath solution containing glucose and substances as indicated.

ATP Assay. For determination of ATP, 20 islets were incubated at a glucose concentration of $6 \mathrm{mM}(0.1 \%$ bovine serum albumin) for 1 hour. Thereafter, the islets were treated with 0.5 or $15 \mathrm{mM}$ glucose for 30 minutes $\left(37^{\circ} \mathrm{C}\right)$. Bath solution was quickly removed and islets were lysed by a solution containing $\mathrm{NaOH}(8 \mathrm{~g} / \mathrm{l})$ and EDTA-di-Na $(0.186 \mathrm{~g} / \mathrm{l})$. ATP was determined according to the manufacturer's protocol (ATP Determination Kit A22066; Invitrogen).

FXR Reporter Assay. Reporter cells (Indigo Bioscience Mouse Farnesoid X Receptor Reporter Assay) expressing the luciferase gene under control of a promotor that is activated by FXR were thawed by the addition of cell recovery medium provided by the manufacturer. One hundred microliters of the cell suspension were used per well. One hundred microliters of treatment medium supplemented with the respective test compounds (atorvastatin, GW4064, mevalonate, or solvent) were added and incubated at $37^{\circ} \mathrm{C}, 5 \% \mathrm{CO}_{2}$ for 24 hours. The next day, medium was removed, detection reagents were added, and luminescence was measured (CLARIOstar; BMG Labtech). Samples were run in duplicate (GW4064) or triplicate (all samples with atorvastatin pretreatment) and were blank corrected for evaluation.

Data Evaluation and Statistical Analysis. All experiments were performed with islets or cells from at least three independent mouse preparations. $\left[\mathrm{Ca}^{2+}\right]_{\mathrm{c}}$ was determined by calculating mean $\left[\mathrm{Ca}^{2+}\right]_{\mathrm{c}}$ over a period of 10 minutes (Fig 2 ) or by determining the area under the curve (AUC) after subtraction of background fluorescence and baseline corretion 10 minutes before changes in bath solution (Fig 3C). For quantification of apoptosis, the percentage of apoptotic 
area in relation to the whole cell area was determined. Membrane potential was analyzed by averaging the values of the last 30 seconds before changes in bath solution. Values are presented as mean \pm S.D. To compare two single groups, Student's $t$ test was performed. For comparison among groups, statistical significance was assessed by ANOVA followed by Student-Newman-Keuls post hoc test. The null hypothesis of each series of experiments was that the test compound has no influence on the respective parameter. Values of $P \leq 0.05$ were considered statistically significant.

\section{Results}

Atorvastatin Decreases Glucose-Stimulated Insulin Secretion. To investigate the effect of atorvastatin on insulin secretion, two incubation periods with different concentrations of the HMG-CoA reductase inhibitor were chosen.

Culturing islets in the presence of $15 \mu \mathrm{M}$ atorvastatin for 24 hours significantly decreased insulin release stimulated by $15 \mathrm{mM}$ glucose. Islets exposed to $1.5 \mu \mathrm{M}$ atorvastatin for 24 hours only showed a tendency to reduced insulin secretion in response to stimulation with $15 \mathrm{mM}$ glucose (Fig. 1A). The culture period in medium supplemented with various concentrations of atorvastatin was extended to 7 days to investigate the influence of time. This prolonged treatment potentiated the detrimental effect of $15 \mu \mathrm{M}$ atorvastatin on glucosestimulated insulin secretion [24 hour: $3.3 \pm 0.9 \mathrm{ng} /($ islet*h), $n=10$, vs. 7 days: $1.3 \pm 0.9 \mathrm{ng} /$ (islet*h), $n=13, P \leq 0.001$ ]. Moreover, already nanomolar concentrations of the statin (150 and $500 \mathrm{nM}$ ) showed a negative effect on insulin release after 7 days (Fig. 1B). Because extension of the time period to 7 days led to stronger variations in secretion among the individual preparations, absolute values were calculated as percentage of control ( $15 \mathrm{mM}$ glucose $)$ in this series of experiments. To investigate whether the reduction of insulin release by atorvastatin is related to inhibition of HMG-CoA reductase, mevalonate $(500 \mu \mathrm{M})$ was added to the culture medium. Mevalonate completely prevented the effect of atorvastatin regarding the 24-hour culture period (Fig. 1C) and partly protected the islets during the extended treatment of 7 days (Fig. 1D).

Atorvastatin Changes Cytosolic $\mathrm{Ca}^{2+}$ but Has No Effect on Cell Viability or ATP Synthesis. Because the rise in $\left[\mathrm{Ca}^{2+}\right]_{\mathrm{c}}$ is crucial for insulin secretion, it was tested whether the inhibitory effect of atorvastatin is caused by changes in $\left[\mathrm{Ca}^{2+}\right]_{\mathrm{c}}$. Incubating islet cells with $15 \mu \mathrm{M}$ atorvastatin for 24 hours slightly altered the $\mathrm{Ca}^{2+}$ response to a glucose stimulus: After exposure to atorvastatin, the first increase in $\left[\mathrm{Ca}^{2+}\right]_{\mathrm{c}}$ in response to $15 \mathrm{mM}$ glucose was approximately half a minute delayed compared with standard conditions (Fig. 2A). Apart from the effect on response time, pretreatment with atorvastatin reduced the mean concentration of $\left[\mathrm{Ca}^{2+}\right]_{\mathrm{c}}$ (Fig. 2B).

Insulin content was not affected even after incubating pancreatic islets in standard culture medium ( $10 \mathrm{mM}$ glucose $)$ supplemented with atorvastatin for the long-term period of 7 days (Fig. 2C). Corresponding to these results, there was no induction of apoptosis by the exposure of islet cells to $15 \mu \mathrm{M}$ atorvastatin in standard culture medium for up to 44 hours compared with the control (\% apoptotic area after 24 hours: control $8.0 \% \pm 1.5 \%$ vs. $15 \mu \mathrm{M}$ atorvastatin, 24 hours, $8.9 \% \pm$ $2.6 \%, n=3$, not significant) (Fig. 2D). As atorvastatin was reported to depolarize mitochondria isolated from rat pancreata and to reduce ATP content of the insulin-secreting cell line INS1 (Sadighara et al., 2017; Urbano et al., 2017), we tested whether atorvastatin affects glucose-stimulated ATP generation in murine islets. ATP content of islets stimulated with 0.5 or $15 \mathrm{mM}$ glucose after 24-hour culture with
A

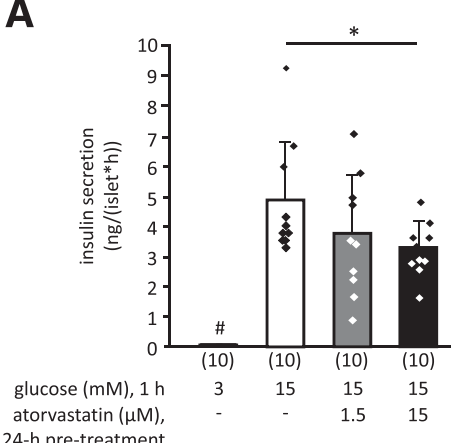
24-h pre-treatment

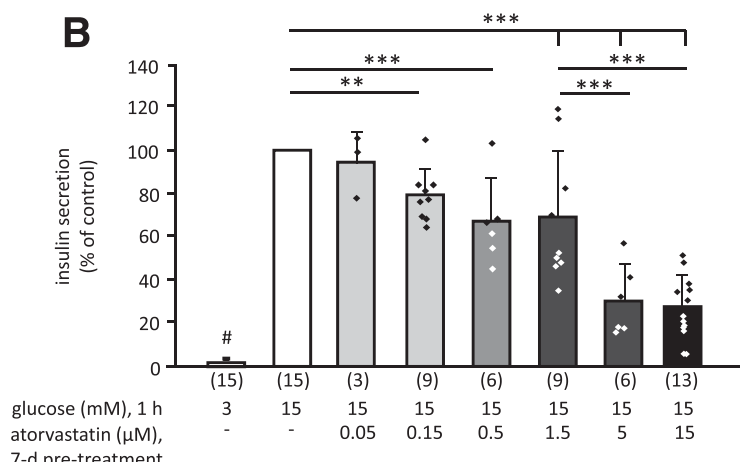

7-d pre-treatment
C

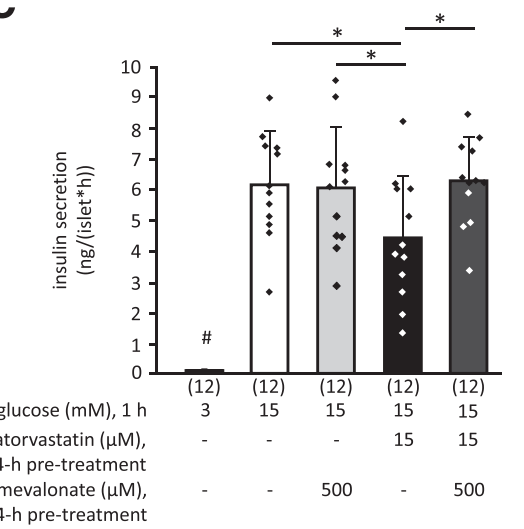

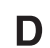

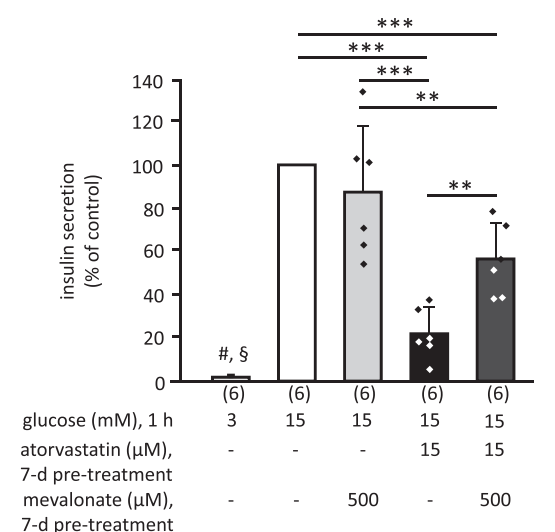

Fig. 1. The influence of atorvastatin on insulin secretion depends on concentration and incubation time. (A) Culturing islets of Langerhans for 24 hours in standard medium supplemented with atorvastatin caused a decrease in glucose-stimulated insulin release (1-hour steady-state incubation) in a concentration-dependent manner. (B) Extending culture time to 7 days significantly increased the damaging effect of the statin. (C and D) The effect was fully prevented (C) or partly reduced (D) by coculture with mevalonate. The number of independent preparations is given below the bars of each diagram. Islets were isolated from female/male mice as follows: 4/6 (A), 6/9 (B), 3/9 (C), $0 / 6$ (D). $\# P \leq 0.001$ vs. all other conditions; $\S P \leq 0.05$ vs. atorvastatin $(\mathrm{D}) ; * P \leq 0.05$; $* * P \leq 0.01 ; * * P \leq 0.001$. 
A

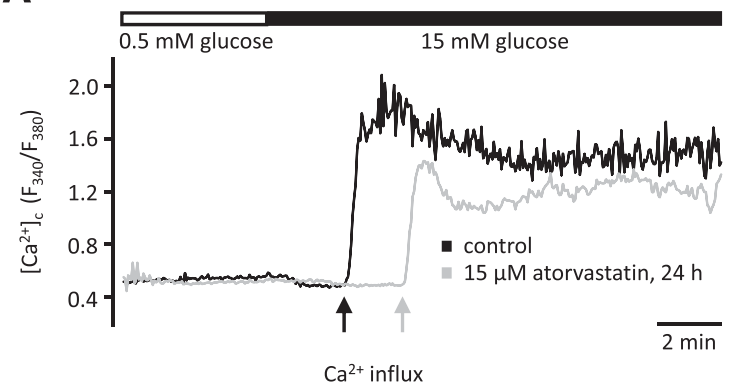

B

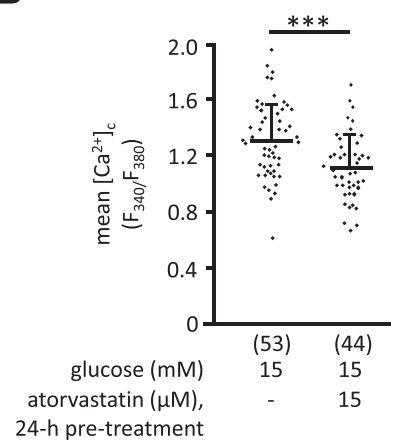

D

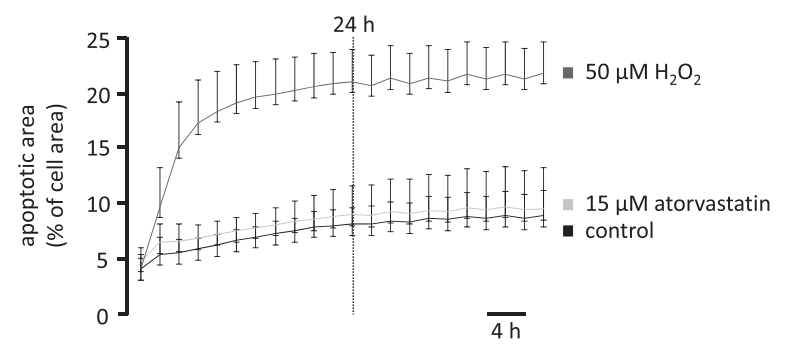

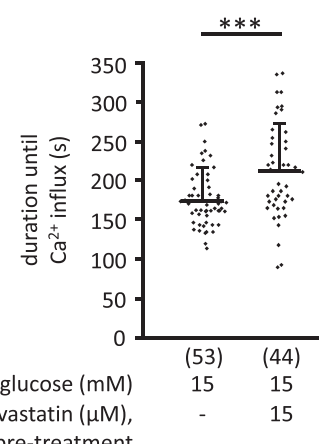

C

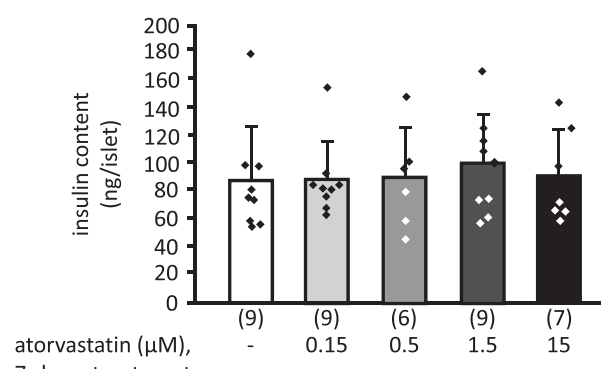

atorvastatin $(\mu \mathrm{M})$,

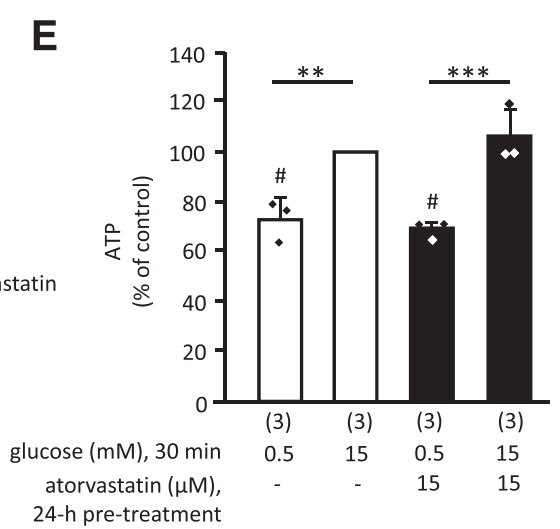

Fig. 2. The detrimental impact of atorvastatin on insulin secretion is associated with altered $\left[\mathrm{Ca}^{2+}\right]_{\mathrm{c}}$ but not with changes in insulin content, apoptosis, or intracellular ATP. (A) After acutely stimulating islet cells with $15 \mathrm{mM}$ glucose the initial increase in $\left[\mathrm{Ca}^{2+}\right]_{\mathrm{c}}$ was delayed in those cells that were exposed to atorvastatin before ( $15 \mu \mathrm{M}, 24$ hours). (B) The increase in $\left[\mathrm{Ca}^{2+}\right]_{\mathrm{c}}$ was reduced as well. (C) No difference in insulin content was observed after culturing islets for 7 days in the presence or absence of atorvastatin $(0.15-15 \mu \mathrm{M})$. (D) Atorvastatin $(15 \mu \mathrm{M})$ did not alter the fraction of apoptotic cell area vs. control. $\mathrm{H}_{2} \mathrm{O}_{2}(50 \mu \mathrm{M})$ was included as a positive control in each experiment. (E) ATP generation in response to 0.5 or $15 \mathrm{mM}$ glucose was not impaired after 24-hour application of atorvastatin. In (A), a representative recording is shown for each condition. The diagram in (B) summarizes the mean $\left[\mathrm{Ca}^{2+}\right]_{\mathrm{c}}$ determined in the first 10 minutes after the rise in $\left[\mathrm{Ca}^{2+}\right]_{\mathrm{c}}$ induced by changing bath solution from 0.5 to $15 \mathrm{mM}$ glucose. The number of cells (A and $\mathrm{B})$ or independent preparations ( $\mathrm{C}$ and $\mathrm{E}$ ) is given below the bars of each diagram. Data presented in (D) are obtained from three independent experiments. Islets were isolated from female/male mice as follows: $0 / 3$ (A and B), 6/3 (C), 3/0 (D), 1/2 (E). $* * P \leq 0.01 ; * * P \leq 0.001 ; \# P \leq 0.01 \mathrm{vs}$. $15 \mathrm{mM}$ glucose + atorvastatin and $15 \mathrm{mM}$ glucose, respectively $(\mathrm{E})$. atorvastatin $(15 \mu \mathrm{M})$ was not different compared with controls (Fig. 2E), excluding severe impairment of mitochondrial function by the drug.

Atorvastatin Abolishes the Insulinotropic Effect of the Bile Acid CDC. To evaluate if atorvastatin influences the FXR or its signaling pathway in pancreatic islets as described for the liver (Fu et al., 2014), the acute effect of the bile acid CDC on insulin secretion was tested after culturing islets under control conditions or in the presence of $15 \mu \mathrm{M}$ atorvastatin for 24 hours. Additionally, $200 \mu \mathrm{M}$ pravastatin were tested under the same conditions.

The acute application of CDC in a concentration of $500 \mathrm{nM}$ enhanced insulin secretion under standard conditions as described earlier (Düfer et al., 2012b). Interestingly, culturing islets with $15 \mu \mathrm{M}$ atorvastatin for 24 hours abolished the acute insulinotropic effect of CDC (Fig. 3A). In this series of experiments, CDC elevated insulin secretion from $3.6 \pm 1.2$ to $4.7 \pm$ $1.7 \mathrm{ng} /\left(\right.$ islet $\left.^{*} \mathrm{~h}\right), n=13, P \leq 0.05$. After culture with $15 \mu \mathrm{M}$ atorvastatin for 24 hours, glucose-stimulated insulin release ( 1 hour) was $2.7 \pm 1.2 \mathrm{ng} /\left(\right.$ islet* $\left.^{*} \mathrm{~h}\right)$ in the absence and $2.5 \pm$ $1.1 \mathrm{ng} /\left(\right.$ islet* $\left.^{*} \mathrm{~h}\right)$ in the presence of CDC (500 nM) $(n=13$, not significant). This was also fact for the lower concentration of
$1.5 \mu \mathrm{M}$ atorvastatin (insulin release in response to $15 \mathrm{mM}$ glucose after 24-hour culture with $1.5 \mu \mathrm{M}$ atorvastatin: $4.1 \pm$ $2.3 \mathrm{ng} /\left(\right.$ islet*h $^{*}$ vs. same conditions + CDC $500 \mathrm{nM}: 4.6 \pm$ $3.4 \mathrm{ng} /($ islet*h), $n=6$, not significant).

The same experiment was performed with pravastatin, which is more hydrophilic than atorvastatin. Twenty-fourhour culture with $200 \mu \mathrm{M}$ pravastatin also inhibited the stimulatory effect of CDC (Fig. 3B), pointing to a class effect of statins [insulin release in response to $15 \mathrm{mM}$ glucose after 24-hour culture with pravastatin: $3.6 \pm 1.5 \mathrm{ng} /\left(\right.$ islet*$\left.^{*} \mathrm{~h}\right) \mathrm{vs}$. same conditions + CDC $500 \mathrm{nM}: 3.1 \pm 1.4 \mathrm{ng} /\left(\right.$ islet $\left.^{*} \mathrm{~h}\right), n=12$, not significant].

Because the effect of CDC on insulin secretion depends on a rise in $\left[\mathrm{Ca}^{2+}\right]_{c}$, this parameter was measured in islet cells and cell clusters that were exposed to $15 \mu \mathrm{M}$ atorvastatin prior to the experiment for 24 hours. $\left[\mathrm{Ca}^{2+}\right]_{\mathrm{c}}$ was determined by calculating the AUC after baseline correction. In agreement with the acute effect on insulin secretion described above, the acute application of $500 \mathrm{nM}$ CDC provoked an increase in $\left[\mathrm{Ca}^{2+}\right]_{\mathrm{c}}$ under control conditions. This was significantly diminished after exposure of the cells to atorvastatin (Fig. 3C), explaining the ineffectiveness of CDC on insulin secretion 
A
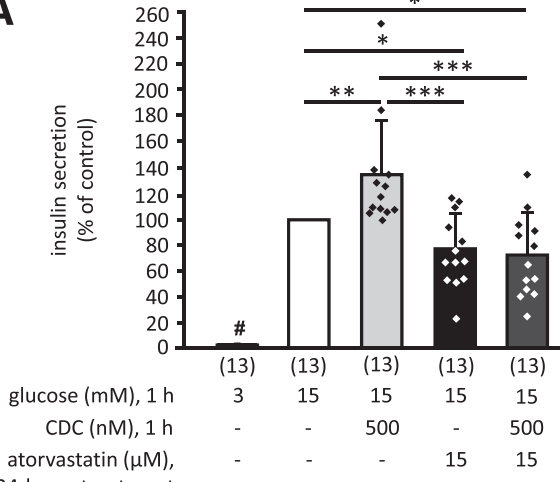

24-h pre-treatment

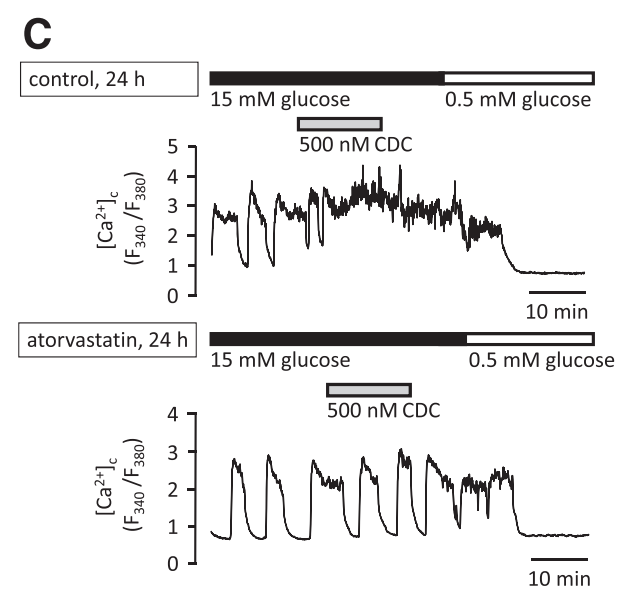

D

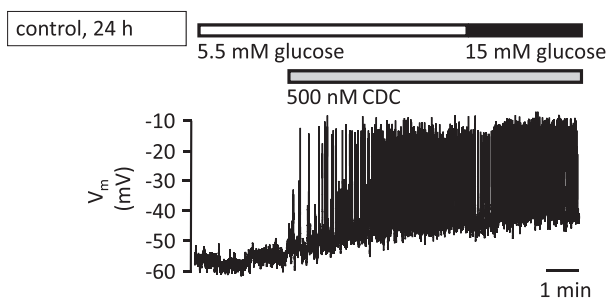

$\overline{1 \min }$

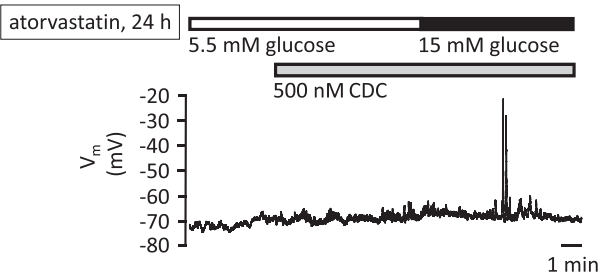

B

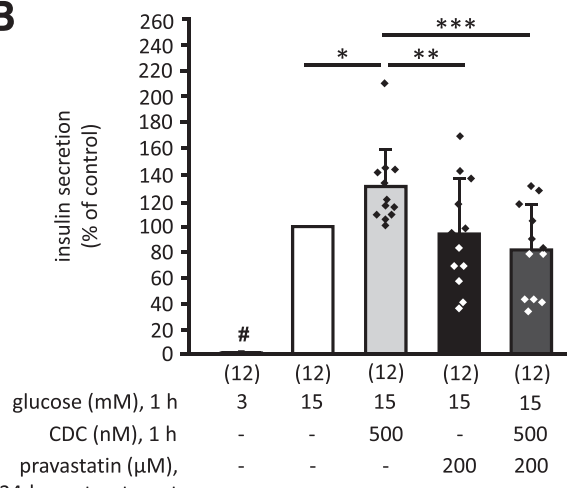

24-h pre-treatment

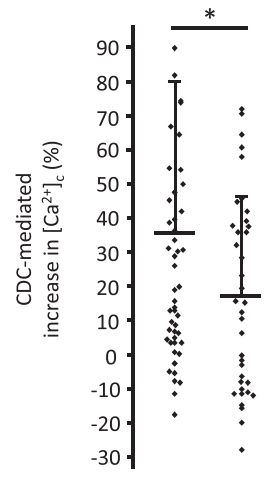

(55) (37)

glucose $(\mathrm{mM})$ $\mathrm{CDC}(\mathrm{nM})$ atorvastatin $(\mu \mathrm{M})$, 24-h pre-treatment
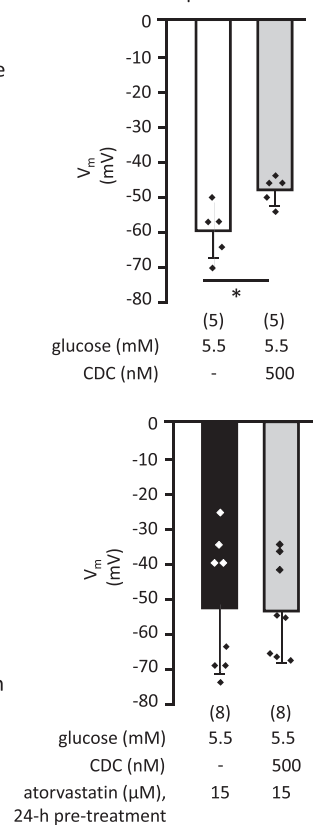

after treatment with the lipophilic statin. Because the effect of bile acids on $\left[\mathrm{Ca}^{2+}\right]_{\mathrm{c}}$ is regulated by electrical activity, a drug eliminating the CDC-induced changes in $\left[\mathrm{Ca}^{2+}\right]_{\mathrm{c}}$ is expected to interact with the influence of CDC on membrane potential. To verify this hypothesis, membrane potential of beta cells was determined in the perforated-patch configuration. These experiments were started in the presence of $5.5 \mathrm{mM}$ glucose, i.e., a concentration in the range of the threshold for induction of $\mathrm{Ca}^{2+}$ action potentials. $\mathrm{CDC}$ was added at a concentration of $500 \mathrm{nM}$ for approximately 7 minutes. If the seal was stable enough, glucose was elevated to $15 \mathrm{mM}$ (CDC still present) at the end of the experiment to verify metabolic integrity. Application of CDC depolarized the membrane in control cells but did not induce any change in cells pretreated with $15 \mu \mathrm{M}$ atorvastatin for 24 hours (Fig. 3D). Of note, most of the atorvastatin-pretreated cells appeared to be more depolarized
Fig. 3. The insulinotropic effect of the bile acid CDC is abolished after exposure to atorvastatin or pravastatin. (A and $\mathrm{B}$ ) ine acute application of $500 \mathrm{nM}$ CDC latory conditions ( $15 \mathrm{mM}$ glucose, 1 hour). After exposure to atorvastatin $(15 \mu \mathrm{M})$ or pravastatin $(200 \mu \mathrm{M})$ for 24 hours, the (C) Under stimulatory conditions $(15 \mathrm{mM}$ glucose), CDC caused a rise in $\left[\mathrm{Ca}^{2+}\right]_{\mathrm{c}}$. Pretreatment with atorvastatin $(15 \mu \mathrm{M})$ for 24 hours significantly reduced the bile acid-mediated increase in $\left[\mathrm{Ca}^{2+}\right]_{\mathrm{c}}$. (D) Under control conditions, CDC induced electrical activity in beta cells in the presence of $5.5 \mathrm{mM}$ glucose. This effect was abolished after pretreatment with atorvastatin $(15 \mu \mathrm{M}, 24$ hours). In ( $\mathrm{C}$ and condition are shown; the diagram in $(\mathrm{C})$ summarizes the percentage increase in $\left[\mathrm{Ca}^{2+}\right]_{\mathrm{c}}$ after application of CDC. $\left[\mathrm{Ca}^{2+}\right]_{\mathrm{c}}$ was determined by calculating the AUC after baseline correction. The diagram in (D) illustrates the evaluation of the membrane potential before and after addition of CDC in control or atorvastatin-treated cells. The number of independent preparabelow the bars of each diagram. Islets were isolated from female/male mice as follows: 6/7 (A), $8 / 4$ (B), $2 / 2$ (C), $2 / 2$ (D). $\# P \leq 0.001$ vs. all other conditions; * $P \leq 0.05$; ** $P \leq 0.01$; $* * * P \leq 0.001$. 
at $5.5 \mathrm{mM}$ glucose compared with the control cells. The lack of effect of CDC after application of the statin supports the idea that these drugs disrupt the coupling of the CDC/FXRpathway and electrical activity, thereby reducing the effect of $\mathrm{CDC}$ on $\mathrm{Ca}^{2+}$ influx.

Atorvastatin Interacts with FXR-Response Elements. To test whether atorvastatin influences the activity of FXR, a mouse luciferase reporter assay was used. Genetically manipulated cells, where expression of luciferase is controlled by an FXR-responsive promotor, were cultured either with $15 \mu \mathrm{M}$ atorvastatin alone or in combination with $1 \mu \mathrm{M}$ of the synthetic FXR activator GW4064 for 24 hours and luciferasecatalzyed changes in bioluminescence were monitored thereafter. Although atorvastatin did not influence FXR activity per se, GW4064-induced activation was dose-dependently diminished (Fig. 4, A and B). Interestingly, additional treatment with mevalonate $(500 \mu \mathrm{M})$ during culture partly protected against the inhibition of FXR by atorvastatin (Fig. 4C).

Because $10 \mu \mathrm{M}$ atorvastatin were reported to activate the CYP-regulating nuclear pregnane $\mathrm{X}$ receptor (PXR) (Howe et al., 2011), we also checked whether activation of this receptor might mimic the negative influence of atorvastatin on insulin release. Therefore, the PXR agonist pregnenolone-16 $\alpha$ alphacarbonitrile was used. 10 or $25 \mu \mathrm{M}$ of this compound only showed a slight, nonsignificant tendency to reduced glucosestimulated insulin release (Fig. 4D) and did not mirror the effect of atorvastatin.

Inhibitory Effect of Atorvastatin in FXR-Deficient Islets. We demonstrated in previous work that the increase in $\left[\mathrm{Ca}^{2+}\right]_{\mathrm{c}}$ in response to bile acids depends on FXR and is absent in beta cells of FXR-KO mice (Düfer et al., 2012b). Consequently, the results described above indicate an interaction between statins and the FXR, leading to elimination of the insulinotropic effect of CDC. This interaction provoked the question whether there might also be an impact vice versa. Therefore, the experiments shown in Fig. 1A were repeated with pancreatic islets from FXR-deficient mice. After exposing FXR-KO islets to different concentrations of atorvastatin for 24 hours, $15 \mu \mathrm{M}$ atorvastatin caused a significant decline in insulin secretion, while a concentration of $1.5 \mu \mathrm{M}-$ similar to
A

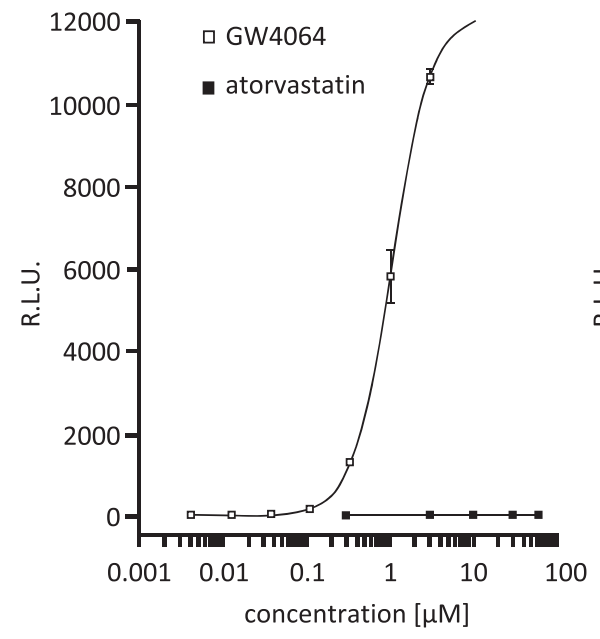

D

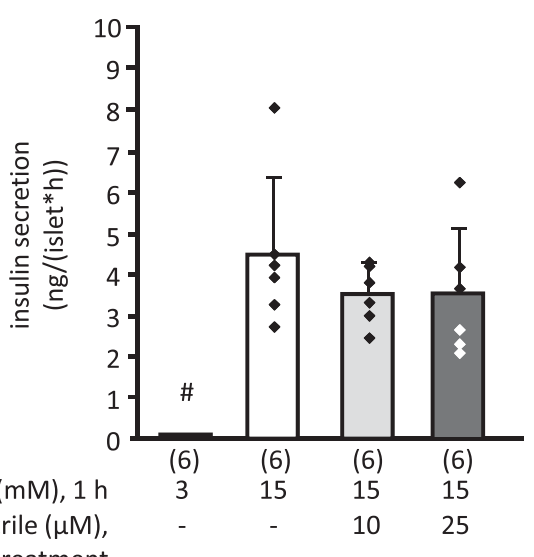

B

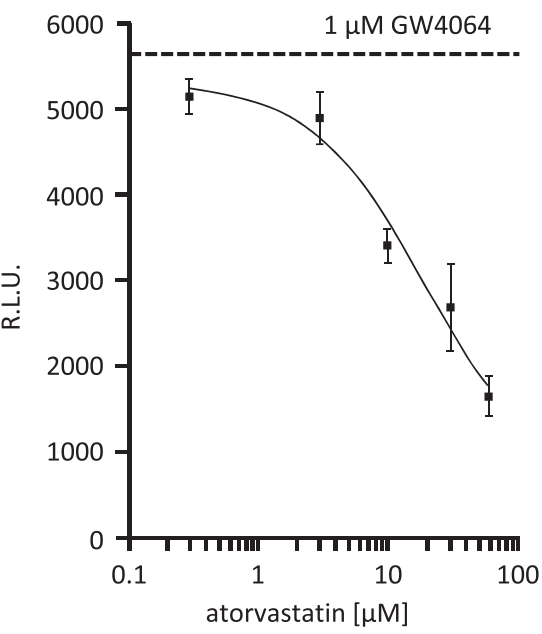

C

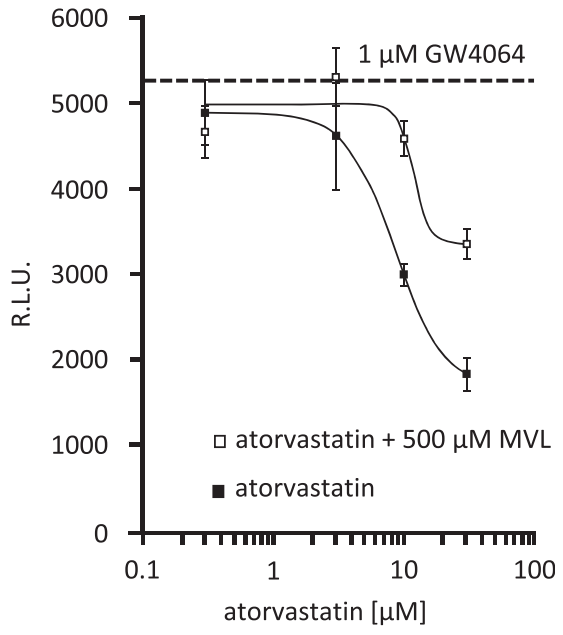

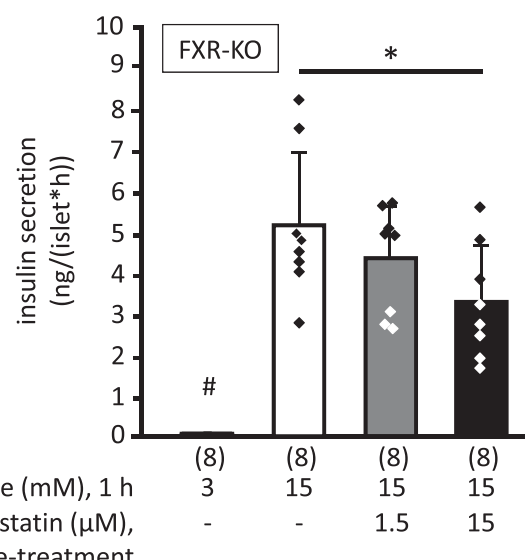

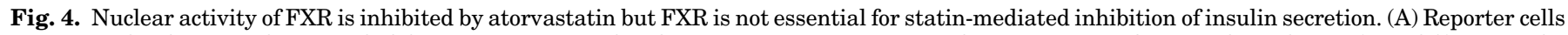

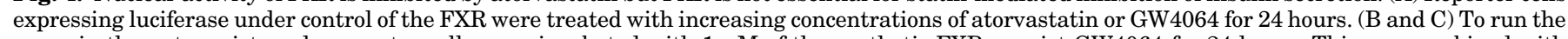

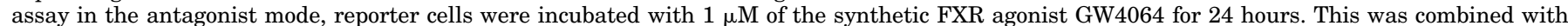

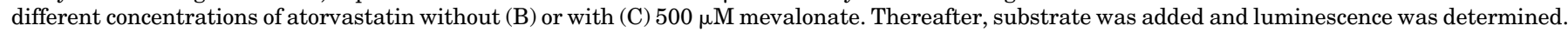

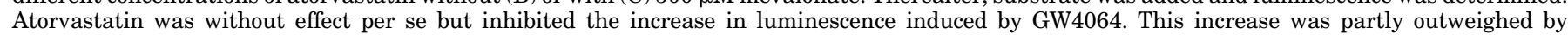

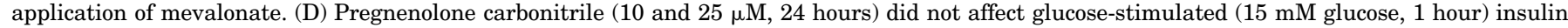

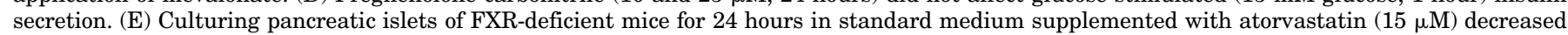

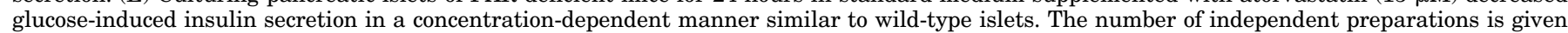
below the bars of the diagram. Islets were isolated from female/male mice as follows: $2 / 4$ (D), $4 / 4(\mathrm{E})$. \#P $\leq 0.001$ vs. all other conditions; $* P \leq 0.05$. 
the effect in wild-type islets-only tended to reduce insulin release (Fig. 4E).

Comparison of the amounts of insulin, secreted in response to $15 \mathrm{mM}$ glucose (1 hour, expressed as percentage of control) after 24-hour culture of the islets with $15 \mu \mathrm{M}$ atorvastatin, revealed no difference between wild-type and FXR-deficient islets [insulin secretion after 24-hour culture with atorvastatin $(15 \mu \mathrm{M})$ : wild-type $64.7 \% \pm 28.9 \%$ of control, $n=27$, vs. FXR-KO $66.6 \% \pm 29.6 \%$ of control, $n=8$, not significant].

FXR Modulates the Damaging Effect of Atorvastatin. Although the experiments with FXR-deficient islets show the independency of the negative effect of atorvastatin on insulin secretion from the nuclear receptor per se, we made a remarkable observation after detailed analysis of the experiments with wild-type islets. Of 27 experiments with wild-type islets, not every preparation responded to the acute application of $500 \mathrm{nM}$ CDC with an increase in insulin secretion under control conditions. Some preparations were nonresponsive to the bile acid, which means that the cytosolic $\mathrm{K}_{\mathrm{ATP}} / \mathrm{Ca}^{2+}$. dependent signaling pathway of FXR is not operative. This might indicate a shift in the localization of FXR from the cytosol to the nucleus of the cell (Schittenhelm et al., 2015). To address this issue, the preparations were divided into two groups, CDC-responsive and CDC-nonresponsive experiments, for subgroup analysis. As a result, we detected a modulatory role of the FXR concerning the degree of damage caused by atorvastatin. Atorvastatin seems to be less harmful when islets are CDC responsive, whereas the inhibitory effect is aggravated when islets are nonresponsive to CDC under control conditions (Fig. 5A): After 24-hour treatment with $15 \mu \mathrm{M}$ atorvastatin, glucose-stimulated insulin secretion was reduced to $77.0 \% \pm$ $28.4 \%$ of control in CDC-responsive preparations $(n=17)$. By contrast, 24-hour treatment of CDC-nonresponsive preparations with atorvastatin lowered glucose-stimulated insulin release to $43.8 \% \pm 14.3 \%$ of control $(n=10)$. It is noteworthy that we observed that the inhibitory effect of atorvastatin on insulin release of CDC-nonresponsive wild-type preparations was higher than in FXR-KO islets (Fig. 5B). This points to a more negative effect of statins when FXR is still present but lost its influence on the cytosolic pathway compared with complete absence of the receptor.

To confirm that FXR influences the damaging effect of atorvastatin, experiments were performed in which the FXR was forced into the nucleus of the cell. To achieve this, islet cells were exposed to the strong, synthetic FXR agonist GW4064 for an extended period. Previous work showed that the cytosolic, $\mathrm{K}_{\mathrm{ATP}}$-dependent signaling pathway of FXR is inactive after prolonged receptor activation by GW4064 (Schittenhelm et al., 2015). To be able to compare the degree of damage caused by atorvastatin as a function of the ability of FXR to act as a cytosolic receptor, only preparations responding to $500 \mathrm{nM} \mathrm{CDC}$ under control conditions, but not after 48hour culture with GW4064, were included. Figure 5C shows that GW4064-treated islets, which have lost the cytosolic pathway of FXR (dark gray vs. light gray bar), were much more sensitive to the inhibitory influence of atorvastatin compared with control (black vs. white bar). As already described above, atorvastatin had only a small effect on islets of CDC-responsive preparations ( $14 \%$ inhibition in this series of experiments). After preincubation of the islets with GW4064 (500 nM) for 24 hours and addition of the statin for another 24 hours, insulin secretion induced by $15 \mathrm{mM}$ glucose was diminished by $80 \%$. Of note, glucose-stimulated insulin release was approximately twofold higher after 48hour culture with GW4064 compared with control.

Finally, the influence of HMG-CoA reductase on the interaction between atorvastatin and CDC/FXR was elucidated. Therefore, mevalonate $(500 \mu \mathrm{M})$ was added to the culture medium in addition to atorvastatin. As expected, CDC did not stimulate insulin release after treatment with atorvastatin for 24 hours. However, stimulation of islets with $500 \mathrm{nM} \mathrm{CDC}$ was clearly improved in those islets where inhibition of endogenous mevalonate synthesis was compensated by external mevalonate supplementation (Fig. 5D).

\section{Discussion}

In accordance with other publications (Zhao and Zhao, 2015; Urbano et al., 2017), incubation of pancreatic islets with atorvastatin reduced insulin secretion. Noteworthy, experiments varied among species and concentration of atorvastatin. We tested atorvastatin in concentrations up to $15 \mu \mathrm{M}$. The high concentration, which exceeds circulating plasma levels in patients, was used to mimic accumulation of the lipophilic drug in vitro within a relatively short period of time because isolated beta cells are difficult to culture for several weeks. To test whether lower concentrations are also effective, we extended our protocol to 7 days. We observed that the effect of atorvastatin is not only dose dependent (Fig. 1A) but also time dependent: Besides the potentiation of the detrimental effect of $15 \mu \mathrm{M}$ atorvastatin, a decrease in insulin release was already provoked by nanomolar concentrations (150 and $500 \mathrm{nM}$ ) of the statin after long-term treatment of 7 days (Fig. 1B). This concentration range is still approximately three- to fourfold higher than plasma concentrations reported in bioequivalence studies (e.g., http://www.mhra.gov.uk/home/ groups/par/documents/websiteresources/con279868.pdf, UK/H/ $3430 / 004 / \mathrm{DC}$ ), but one must keep in mind that in vitro the drug has to cross the barrier of connective tissue surrounding murine islets and is not distributed via systemic circulation.

The inhibitory effect of atorvastatin was not accompanied by a decrease in glucose-stimulated ATP synthesis but involves changes in $\mathrm{Ca}^{2+}$ influx (Fig. 2, A, B, and E), which points to an interaction with the triggering pathway that regulates beta cell function. Even though the exact mechanism remains to be elucidated, the diabetogenic effect of atorvastatin is unquestioned. Insulin content was not altered between control or any of the applied concentrations of atorvastatin even after 7 days (Fig. 2C). However, glucose-stimulated insulin release could be fully restored when mevalonate was added to the islets during the 24-hour culture with atorvastatin. This suggests that downstream metabolites of the cholesterol biosynthesis pathway are involved. The mevalonate rescue was only partial in the long-term experiments of 7 days, indicating that the deleterious effect of atorvastatin does not completely depend on inhibition of HMG-CoA reductase. Because some statins activate the xenobiotic receptor PXR (Howe et al., 2011), we tested whether the known PXR agonist pregnenolone carbonitrile induces inhibitory effects similar to atorvastatin. The lack of any significant effect after 24-hour culture (Fig. 4D) argues against a major role of such an interaction in beta cells.

In contrast to reports of others (Zhao and Zhao, 2015; Sadighara et al., 2017), we could not attribute the detrimental effect on insulin secretion to changes in cell viability. 
A

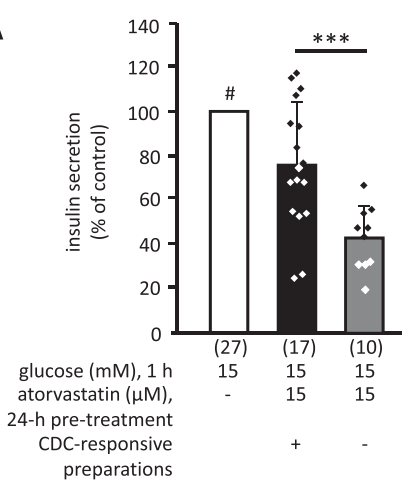

C

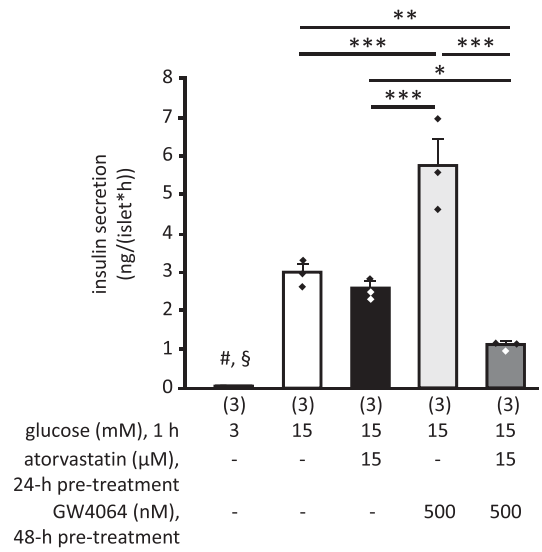

B
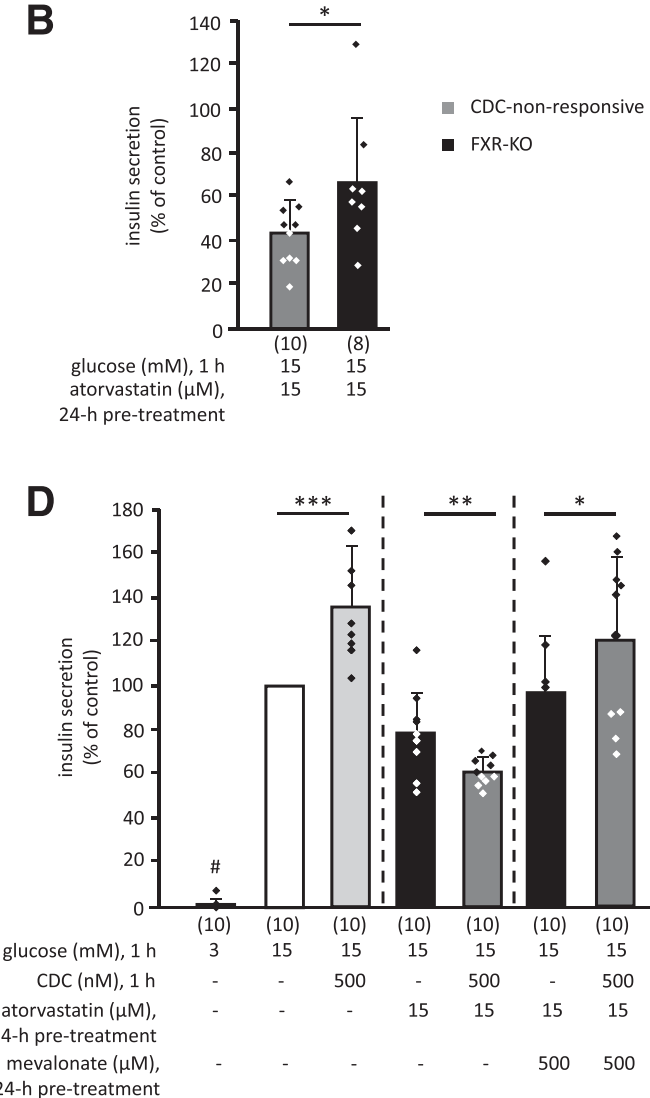

Fig. 5. FXR modulates the negative effect of atorvastatin depending on the responsivity of the islets to CDC. (A) The degree of inhibition caused by atorvastatin $(15 \mu \mathrm{M}$ ) was more pronounced in preparations that were nonresponsive to $500 \mathrm{nM}$ CDC (gray bar) under standard conditions (i.e., 1-hour stimulation with $15 \mathrm{mM}$ glucose) compared with those 17 out of 27 preparations that showed a potentiating effect in response to CDC (black bar). (B) CDCnonresponsive islet preparations were more sensitive to statin-induced reduction of insulin release than FXR-KO islets. (C) Islets were cultured with GW4064 (500 nM) for 48 hours. After 24 hours, atorvastatin $(15 \mu \mathrm{M})$ was added for 24 hours. For evaluation, only those preparations were included in which GW4064 abolished the acute stimulatory effect of CDC. In these preparations, atorvastatin only tended to decrease insulin release in response to $15 \mathrm{mM}$ glucose (black vs. white bar). In islets exposed to GW4064 before and during atorvastatin treatment (dark gray bar) the inhibitory effect was drastically increased compared with both GW4064-treated and control islets. (D) Addition of mevalonate during the 24-hour culture partly restored the responsivity of islets to acute stimulation with CDC. Dashed lines mark the groups chosen for statistic comparison. The number of independent preparations is given below the bars of each diagram. Islets were isolated from female/male mice as follows: $12 / 15$ (A), $6 / 12$ (B), $3 / 0$ (C), $6 / 4$ (D). $\# P \leq 0.001$ (A, C, and D) vs. all other conditions; $\S P \leq 0.05$ vs. atorvastatin and GW4064; $* P \leq 0.05 ; * * P \leq 0.01 ; * * P \leq 0.001$.

These discrepancies might result from different experimental approaches, as the effect of atorvastatin on cytochrome c release was monitored in isolated mitochondria (Sadighara et al., 2017) and cell survival was investigated by an assay testing the metabolic activity via reduction of dimethyl-thiazolyl-tetrazolium salt (MTT assay), which does not give any information about apoptosis (Zhao and Zhao, 2015). In summary, an effect of atorvastatin on insulin biosynthesis or a dramatic loss of beta cell mass can be ruled out as explanations for the decrease in insulin release in our investigation.

Our data show for the first time that statins interfere with the insulinotropic effect of bile acids. In the postprandial state, plasma levels of bile acids can rise up to $15 \mu \mathrm{M}$ (Everson, 1987; Houten et al., 2006). This is not only necessary for the absorption of lipids but also important for lowering blood sugar peaks by stimulation of insulin secretion. The stimulatory effect of the FXR-agonistic bile acid CDC, which we already described in our previous investigations (Düfer et al., 2012b; Schittenhelm et al., 2015), was clearly seen under control conditions but completely disappeared after 24-hour culture with atorvastatin or pravastatin (Fig. 3, A and B). Corresponding to this loss of efficacy on glucose-stimulated insulin release, the influence of CDC on membrane potential was impaired and the CDC-mediated increase in $\left[\mathrm{Ca}^{2+}\right]_{\mathrm{c}}$ was reduced to less than $50 \%$ (Fig. 3, C and D). For patients being treated with statins, this implies not only a decline in islet function induced by the statin per se but also the loss of an important physiologic regulatory function of bile acids for glucose homeostasis. In addition, a reduction of the postprandial plasma concentrations of bile acids was reported in patients with obesity (Glicksman et al., 2010) and patients who are prediabetic (Shaham et al., 2008), actually patient groups with the common indication for cholesterollowering drugs such as statins. Taken together, the already reduced contribution of bile acids to the postprandial regulation of blood glucose concentration in those patients would be progressively more or, worst case, entirely abolished during long-term therapy with statins. The exact mechanism leading to inhibition of the effect of CDC needs to be further investigated. Because the link between FXR activation and $\mathrm{K}_{\mathrm{ATP}}$ channel closure has not yet been clearly identified, it might be possible that incubation with atorvastatin interferes with some target downstream to FXR, but upstream to the closure of $\mathrm{K}_{\mathrm{ATP}}$ channels. Bearing in mind that statins impair the prenylation and thereby regulation of proteins by inhibiting 
the mevalonate pathway ( $\mathrm{Li}$ et al., 1993), atorvastatin could disrupt some factor derived from this pathway linking FXR stimulation to $\mathrm{K}_{\mathrm{ATP}}$ channel closure. In agreement with this assumption, coculture with mevalonate rescued the sensitivity of islets to acute stimulation with CDC (Fig. 5D).

Furthermore, our results demonstrate that the interference between atorvastatin and the FXR is not unilateral but of a bidirectional character. The experiments with FXR-KO islets show that the impairing effect induced by atorvastatin is partly independent of FXR (Fig. 4E). But in addition, our data reveal that FXR plays a modulatory role with regard to the degree of damage caused by the statin (Fig. 5, A and B). The availability of the receptor in the cytosol seems to be crucial for this modulation. Apparently, a localization close to the plasma membrane that enables interaction of FXR with the cytosolic triggering pathway for insulin secretion via $\mathrm{K}_{\mathrm{ATP}}$ channel closure and $\mathrm{Ca}^{2+}$ influx is protective and reduces the negative effect of atorvastatin on insulin release. Disruption of this pathway is associated with an increased inhibitory effect of statins on insulin release (Fig. 5C).

Popescu et al. (2010) detected a translocation of the FXR into the nucleus in obese $o b / o b$ mice, whereas the receptor is mainly located in the cytosol in wild-type beta cells. Howe et al. (2011) reported that atorvastatin was not able to activate the FXR. We confirmed this result in a mouse FXR reporter assay. Furthermore, we demonstrate for the first time that atorvastatin inhibits nuclear FXR activity (Fig. 4B). If this also applies to pancreatic beta cells, suppression of genes important for insulin secretion might explain the increased level of beta cell failure under conditions where the FXR is forced to translocate into the nucleus. Astonishingly, the inhibitory influence of atorvastatin on luciferase expression was reduced by mevalonate. This may further support the idea that HMG-CoA reductase-dependent modifications of FXR are generally required for regular functions of the receptor with respect to both cytosolic and nuclear signaling. The nature of these alterations as well as the FXR-regulated target genes that are suppressed by atorvastatin have to be characterized in further studies.

With respect to the pathway described above, differences in receptor localization - and thereby in receptor functionbetween lean and obese organisms might be critical determinants for the statin-bile acid interaction. In line with the idea of fundamental differences in FXR function, dependent on body weight and/or lipid homeostasis, it was reported that ablation of FXR is associated with decreased insulin secretion and insulin content under control conditions as well as peripheral insulin resistance (Cariou et al., 2006; Popescu et al., 2010). However, these negative characteristics completely change in a glucolipotoxic environment. FXR-deficient islets were resistant to glucolipotoxicity, whereas wild-type islets kept in glucolipotoxic medium showed an impaired glucose-stimulated insulin release (Schittenhelm et al., 2015). Supporting the hypothesis that-in beta cells - cytosolic localization of FXR is a prerequisite for its positive impact on cellular function, Schittenhelm et al. (2015) demonstrated that the potentiating effect of FXR agonists on insulin secretion is lost in islets derived from mice after high-fat diet. Taken together, these data suggest that certain conditions (i.e., genetic or diet-induced obesity in vivo, glucolipotoxicity or prolonged receptor activation in vitro) disrupt the cytosolic interaction between FXR and $\mathrm{K}_{\mathrm{ATP}}$ channels and might thereby aggravate the diabetogenic risk of statins. It is tempting to speculate that patients with obesity might be exceptionally sensitive to statin-induced beta cell damage as-similar to the genetic mouse model or to islets kept in a glucolipotoxic environment-their profile of FXR distribution and interaction may change during disease. Therefore, they not only lose the beneficial effect of bile acids on the endocrine pancreas but also risk progression of beta cell failure by direct statin-induced impairment of glucosestimulated insulin release.

\section{Acknowledgments}

We thank Melanie Arning for excellent technical assistance.

\section{Authorship Contributions}

Participated in research design: Hoffmeister, Drews, Düfer.

Conducted experiments: Hoffmeister, Kaiser, Lüdtke.

Performed data analysis: Hoffmeister, Kaiser, Lüdtke, Düfer.

Wrote or contributed to the writing of the manuscript: Hoffmeister, Kaiser, Lüdtke, Drews, Düfer.

\section{References}

Cariou B, van Harmelen K, Duran-Sandoval D, van Dijk TH, Grefhorst A, Abdelkarim M, Caron S, Torpier G, Fruchart J-C, Gonzalez FJ, et al. (2006) The farnesoid X receptor modulates adiposity and peripheral insulin sensitivity in mice. J Biol Chem 281:11039-11049.

Düfer M, Hörth K, Krippeit-Drews P, and Drews G (2012a) The significance of the nuclear farnesoid X receptor (FXR) in $\beta$ cell function. Islets 4:333-338.

Düfer M, Hörth K, Wagner R, Schittenhelm B, Prowald S, Wagner TFJ, Oberwinkler J, Lukowski R, Gonzalez FJ, Krippeit-Drews P, et al. (2012b) Bile acids acutely stimulate insulin secretion of mouse $\beta$-cells via farnesoid $\mathrm{X}$ receptor activation and $\mathrm{K}_{\mathrm{ATP}}$ channel inhibition. Diabetes 61:1479-1489.

Everson GT (1987) Steady-state kinetics of serum bile acids in healthy human subjects: single and dual isotope techniques using stable isotopes and mass spectrometry. J Lipid Res 28:238-252.

Fiorucci S, Mencarelli A, Palladino G, and Cipriani S (2009) Bile-acid-activated receptors: targeting TGR5 and farnesoid-X-receptor in lipid and glucose disorders. Trends Pharmacol Sci 30:570-580.

Fu ZD, Cui JY, and Klaassen CD (2014) Atorvastatin induces bile acid-synthetic enzyme Cyp7a1 by suppressing FXR signaling in both liver and intestine in mice. $J$ Lipid Res 55:2576-2586.

Glicksman C, Pournaras DJ, Wright M, Roberts R, Mahon D, Welbourn R, Sherwood R, Alaghband-Zadeh J, and le Roux CW (2010) Postprandial plasma bile acid responses in normal weight and obese subjects. Ann Clin Biochem 47:482-484.

Habeos I, Ziros PG, Psyrogiannis A, Vagenakis AG, and Papavassiliou AG (2005) Statins and transcriptional regulation: the FXR connection. Biochem Biophys Res Commun 334:601-605.

Houten SM, Watanabe M, and Auwerx J (2006) Endocrine functions of bile acids. EMBO J 25:1419-1425.

Howe K, Sanat F, Thumser AE, Coleman T, and Plant N (2011) The statin class of HMG-CoA reductase inhibitors demonstrate differential activation of the nuclear receptors PXR, CAR and FXR, as well as their downstream target genes. Xenobiotica 41:519-529.

Huber RM, Murphy K, Miao B, Link JR, Cunningham MR, Rupar MJ, Gunyuzlu PL, Haws TF, Kassam A, Powell F, et al. (2002) Generation of multiple farnesoid-Xreceptor isoforms through the use of alternative promoters. Gene 290:35-43.

Li G, Regazzi R, Roche E, and Wollheim CB (1993) Blockade of mevalonate production by lovastatin attenuates bombesin and vasopressin potentiation of nutrient-induced insulin secretion in HIT-T15 cells. Probable involvement of small GTP-binding proteins. Biochem J 289:379-385.

Makishima M, Okamoto AY, Repa JJ, Tu H, Learned RM, Luk A, Hull MV, Lustig KD, Mangelsdorf DJ, and Shan B (1999) Identification of a nuclear receptor for bile acids. Science 284:1362-1365.

Parks DJ, Blanchard SG, Bledsoe RK, Chandra G, Consler TG, Kliewer SA, Stimmel JB, Willson TM, Zavacki AM, Moore DD, et al. (1999) Bile acids: natural ligands for an orphan nuclear receptor. Science 284:1365-1368.

Popescu IR, Helleboid-Chapman A, Lucas A, Vandewalle B, Dumont J, Bouchaert E, Derudas B, Kerr-Conte J, Caron S, Pattou F, et al. (2010) The nuclear receptor FXR is expressed in pancreatic beta-cells and protects human islets from lipotoxicity. FEBS Lett 584:2845-2851.

Sadighara M, Amirsheardost Z, Minaiyan M, Hajhashemi V, Naserzadeh P, Salimi A, Seydi E, and Pourahmad J (2017) Toxicity of atorvastatin on pancreas mitochondria: a justification for increased risk of diabetes mellitus. Basic Clin Pharmacol Toxicol 120:131-137.

Sattar N, Preiss D, Murray HM, Welsh P, Buckley BM, de Craen AJM, Seshasai SRK, McMurray JJ, Freeman DJ, Jukema JW, et al. (2010) Statins and risk of incident diabetes: a collaborative meta-analysis of randomised statin trials. Lancet 375:735-742.

Scandinavian Simvastatin Survival Study study group (1994) Randomised trial of cholesterol lowering in 4444 patients with coronary heart disease: the Scandinavian Simvastatin Survival Study (4S). Lancet 344:1383-1389.

Schittenhelm B, Wagner R, Kähny V, Peter A, Krippeit-Drews P, Düfer M and Drews G (2015) Role of FXR in $\beta$-cells of lean and obese mice. Endocrinology 156:1263-1271. 
Sever PS, Dahlöf B, Poulter NR, Wedel H, Beevers G, Caulfield M, Collins R, Kjeldsen SE, Kristinsson A, McInnes GT, et al.; ASCOT investigators (2003) Prevention of coronary and stroke events with atorvastatin in hypertensive patients who have average or lower-than-average cholesterol concentrations, in the AngloScandinavian Cardiac Outcomes Trial--Lipid Lowering Arm (ASCOT-LLA): a multicentre randomised controlled trial. Lancet 361:1149-1158.

Shaham O, Wei R, Wang TJ, Ricciardi C, Lewis GD, Vasan RS, Carr SA, Thadhani R, Gerszten RE, and Mootha VK (2008) Metabolic profiling of the human response to a glucose challenge reveals distinct axes of insulin sensitivity. Mol Syst Biol 4:214.

Sinal CJ, Tohkin M, Miyata M, Ward JM, Lambert G, and Gonzalez FJ (2000) Targeted disruption of the nuclear receptor FXR/BAR impairs bile acid and lipid homeostasis. Cell 102:731-744.

Thompson PD, Panza G, Zaleski A, and Taylor B (2016) Statin-associated side effects. $J$ Am Coll Cardiol 67:2395-2410.

Urbano F, Bugliani M, Filippello A, Scamporrino A, Di Mauro S, Di Pino A, Scicali R Noto D, Rabuazzo AM, Averna M, et al. (2017) Atorvastatin but not pravastatin impairs mitochondrial function in human pancreatic islets and rat $\beta$-cells. Direct effect of oxidative stress. Sci Rep 7:11863.

Yada T, Nakata M, Shiraishi T, and Kakei M (1999) Inhibition by simvastatin, but not pravastatin, of glucose-induced cytosolic $\mathrm{Ca}^{2+}$ signalling and insulin secretion due to blockade of L-type $\mathrm{Ca}^{2+}$ channels in rat islet beta-cells. $\mathrm{Br}$ J Pharmacol 126: 1205-1213.

Yaluri N, Modi S, López Rodríguez M, Stančáková A, Kuusisto J, Kokkola T, and Laakso M (2015) Simvastatin impairs insulin secretion by multiple mechanisms in MIN6 cells. PLoS One 10:e0142902.

Zhao W and Zhao S-P (2015) Different effects of statins on induction of diabetes mellitus: an experimental study. Drug Des Devel Ther 9:6211-6223.

Address correspondence to: Dr. Martina Düfer, Pharmaceutical and Medicinal Chemistry, Dept. of Pharmacology, PharmaCampus, Corrensstraße 48, 48149 Münster, Germany. E-mail: martina.duefer@uni-muenster.de 